\title{
Novedades de Jurisprudencia
}

\author{
Fernando Amosa ${ }^{1}$ \\ Universidad Católica de La Plata - Argentina \\ Juan Francisco Díaz \\ Universidad Nacional de La Plata - Argentina
}

Revista Derechos en Acción ISSN 2525-1678/ e-ISSN 2525-1686

Año 5/No 14, Verano 2019-2020 (21 diciembre a 20 marzo), 656-676

DOI: https://doi.org/10.24215/25251678e370

ORCID: https://orcid.org/0000-0002-2706-1650

https://orcid.org/0000-0002-5891-7845

\section{Novedades de la Corte Suprema de Justicia de la Nación}

La Corte Suprema revocó la condena impuesta a un diario y a sus editores por un artículo de un columnista

El máximo tribunal nacional resolvió revocar una condena civil contra el diario pampeano "La Arena" y sus editores por un artículo cuya autoría corresponde a un columnista que, aun cuando fuera un colaborador habitual del diario, no autorizaba a concluir que el medio había compartido o había hecho suyas las opiniones o el contenido del artículo en cuestión.

La condena original, había sido impuesta a Juan José Reyes, a los editores y al Diario "La Arena" por un artículo publicado en aquel medio en enero de 2005 , donde se refería una supuesta donación "trucha" de un predio para la construcción del edificio

\footnotetext{
Abogado (UCALP), docente del Instituto Provincial de la Administración Pública (IPAP) y asistente jurídico del Ministerio de Jefatura de Gabinete de Ministros de la Provincia de Buenos Aires. Email: Fernando.amosa@gmail.com

2 Abogado (UNLP), docente de la Facultad de Ciencias Jurídicas y Sociales de la UNLP. Email: juanfranciscodiaz87@gmail.com
} 
donde iba a funcionar un nuevo centro de contención de menores en las afueras de la ciudad de Santa Rosa (CSJN, "García Stella Marys y otro c/ Reyes Juan José y otros s/ daños y perjuicios", 3 de diciembre de 2019).

El carácter inerte de la cosa no obsta a que sea considerada riesgosa

Así lo expresó la Corte Suprema en una causa en que una señora demandó por los daños sufridos al caer de una escalera, que no poseía barandas, por la que se accedía a un camión ubicado en la Ciudad Autónoma de Buenos Aires con el fin de hacer publicidad turística de la Provincia de Salta.

En el año 2003, Ana María Bergerot, docente de 59 años, se cayó de la escalera metálica -sin barandas- por la que se accedía a un camión ubicado en la Ciudad Autónoma de Buenos Aires con el fin de hacer publicidad turística de la Provincia de Salta. La caída desde una altura aproximada de 1,5 metros, le produjo golpes en la cabeza, hombro y costillas, lo que acarreo como consecuencia una incapacidad del $19 \%$ de la total obrera.

La Corte determinó que si la escalera sin barandas, a pesar de ser una cosa inactiva, era o no riesgosa o viciosa, carácter que debe ser probado por quien lo alega -el damnificado-, además de la relación de causalidad entre el riesgo o vicio y el perjuicio. Al respecto, deja sentado el máximo tribunal que el carácter inerte de la cosa no obsta la aplicación de las normas que regulan la responsabilidad por el daño ocasionado por una cosa o riesgosa (art. 1113 del CC -actual 1757 del CCC-). Si la cosa inerte tiene participación activa en la producción del daño sufrido por quien la utiliza nada excluye la responsabilidad legalmente atribuida al dueño o al guardián. (CSJN, "Bergerot, Ana María c/ Salta, Provincia de y otros s/ daños y perjuicios", 12 de diciembre de 2019).

La Corte confirmó una sentencia que condenó a Arcor por la aparición de una pieza dentaria en una barra de cereal

El caso se trata de una consumidora residente en la provincia de Chaco que encontró una pieza dentaria en el interior de 
una barra de cereal. La Corte Suprema desestimó el recurso de queja interpuesto por la compañía, lo que deja firme la sentencia de condena de la Cámara en lo Contencioso Administrativo de Única Instancia de la Primera Circunscripción Judicial de la Provincia del Chaco (CSJN, "Barcia, Stella Maris c/ Telecentro y otros s/ supuesta infracción a la Ley Nacional $\mathrm{n}^{\circ} 24.240$ y sus modificatorias», 17 de diciembre de 2019).

\section{La Corte Suprema absolvió a Cristina Vázquez y Lucia Rojas}

La Corte Suprema de Justicia de la Nación absolvió a Cristina Liliana Vázquez y a Lucía Cecilia Rojas, tras más de nueve años en lo que se consideró un proceso indebido. Las mujeres habían sido condenadas por todas las instancias judiciales de la provincia de Misiones, imputadas por el homicidio de Ersélida Dávalos ocurrido en la ciudad de Posadas en el año 2001.

La primera condena se conoció en el año 2010, condenándolas bajo la figura de "homicidio criminis causa". En ese momento la resolución fue apelada llegando por primera vez, en el año 2015 y 2016, a los estrados de la Corte, donde se dispuso dejar sin efecto el decisorio y ordenar al tribunal de origen la revisión de la condena a partir de las reglas de la sana crítica y de la aplicación de un método racional de reconstrucción histórica. Esa exigencia se tradujo en un nuevo pronunciamiento condenatorio en el año 2016, lo que produjo la interposición de recursos extraordinarios federales.

Esta vez, el más alto tribunal del país, consideró que, el punto central sobre el que debía expedirse era el derecho que le asiste a todo condenado de recurrir la sentencia; con una revisión amplia y sin la necesidad que dicho obrar deba ser recordado por una máxima instancia constitucional. Evidenció las insuficiencias en el examen de la versión de las imputadas con relación a su completa ajenidad a los hechos atribuidos, recordando la importancia de la presunción de inocencia hasta que un juicio respetuoso del debido proceso demuestre la culpabilidad traducida en una sentencia firme. Entendió que no correspondía devolver la causa para el dictado de un 
nuevo decisorio, ya que implicaría, tras más de nueve años de procedimiento recursivo, una patente inseguridad jurídica para las acusadas, sin poder poner término al estado de sospecha producto de la acusación (CSJN, "Expte. N 48669/2015 (Ex N 340/2010) -Defensora Oficial de Instrucción' N 2 - Dra. Criseida Moreira s/recurso de casación en autos expte. $N$ 122(A) 10 Dr. Venialgo s/rec. de casación en autos: 430-2007 Rojas, Lucía Cecilia; Jara, Ricardo Omar; Vázquez, Cristina s/ homicidio agravado", 26 de diciembre de 2019).

La Corte definió la competencia de la Justicia Contencioso Administrativo Federal para conocer en un causa del Estado Nacional contra Barrick Gold

La Corte Suprema definió que la Justicia Contencioso Administrativo Federal es competente para conocer en una acción de amparo iniciada por el Ministerio de Medio Ambiente y Desarrollo Sustentable de la Nación contra la empresa Minera Argentina Gold S.R.L.-explotadora de Barrick Gold- a efectos de que la justicia le ordene el cumplimiento del Plan de Adecuación y mejora continua de las instalaciones y procedimiento de operación del Sistema de Lixiviación en Valle (SLV) a los fines de prevenir la ocurrencia de futuros incidentes (CSJN, "Torres, José y otro c/Barrick y/o Minera Gold s/amparo (inc. de inbibitoria)", 26 de diciembre de 2019).

\section{El idioma nacional no es una condición imprescindible para el ejercicio de derechos políticos de extranjeros}

Así lo definió la Corte Suprema de Justicia de la Nación, al revocar una decisión de la Sala II de la Cámara Federal La Plata que había considerado que el conocimiento del idioma castellano era necesario para obtener la ciudadanía argentina. El Máximo Tribunal señaló que la conveniencia de establecer esta exigencia y el alcance de ese requisito es potestad exclusiva del legislador (CSJN, "Liu, Cairong s/ solicitud carta de ciudadania”, 11 de febrero de 2020). 
Un hecho reconocido y no controvertido no merece ser probado

El Máximo Tribunal revocó la sentencia de la Sala VII de la Cámara Nacional de Apelaciones del Trabajo que había otorgado el resarcimiento a un trabajador por los daños padecidos, y desconocido la pretensión de la ART, a raíz de un accidente durante el desplazamiento desde su domicilio al trabajo. La Aseguradora, reclamaba la deducción de la condena de lo percibido extrajudicialmente que había sido admitido expresamente por el actor en la demanda.

Contra la decisión de la Cámara laboral, la aseguradora interpuso recurso extraordinario, el cuál fue rechazado. Su denegación, originó la queja que dio lugar al pronunciamiento de la Corte.

La Corte Suprema remarcó que, su decisión implicaba hacer una excepción a las prescripciones del artículo 14 de la Ley 48 que habilitan la vía ante dicho organismo. En su fundamento explicó que, si bien la impugnación articulada remite al examen de una cuestión fáctica, probatoria y de derecho común y procesal, la misma redunda en un menoscabo del derecho de defensa de la apelante (CSIN, "López, Marcelo Javier c/ Provincia ART S.A. s/ accidente - ley especial", 18 de febrero de 2020").

\section{Novedades de la Suprema Corte de Justicia de la Provincia de Buenos Aires}

\section{Confirmaron la condena al futbolista Alexis Zárate por abuso sexual}

Con el voto de los jueces Soria, Kogan, Pettigiani y Genoud, la Suprema Corte de Justicia de la provincia de Buenos Aires decidió rechazar el recurso extraordinario de inaplicabilidad de ley interpuesto por la defensa de Alexis Zárate y confirmo la condena a 6 años y 6 meses de prisión impuesta al futbolista por el Tribunal en lo Criminal $\mathrm{N}^{\circ} 1$ de Lomas de Zamora, por encontrarlo culpable del delito de abuso sexual con acceso carnal. 
El hecho por el que fue condenado Alexis Zárate, ocurrió en la mañana del día 16 de marzo de 2014, cuando el futbolista ingresó a la habitación donde se encontraba la víctima junto a su compañero de equipo, Martín Benítez, la penetró y eyaculó contra su voluntad, según surge de la sentencia del máximo tribunal bonaerense.

Para llegar a la Corte, los abogados de Zárate habían esgrimido que, a pesar de que el futbolista reconoció haber mantenido relaciones sexuales con la víctima, no se había llegado a acreditar el abuso sexual, lo que implicaba una vulneración a su derecho de defensa.

Dentro de sus fundamentos, la Corte destacó que tanto en la acusación como la sentencia, se especificó el lugar físico donde se produjo el abuso, las características de las afrentas sexuales y el marco temporal en que sucedió, sin que se viole su derecho de defensa ni que la sentencia padezca vicios de arbitrariedad e incongruencia (SCBA, "Zárate Maldonado, Alexis Joel s/ Recurso extraordinario de inaplicabilidad de ley en causa $n^{\circ} 87.295$ del Tribunal de Casación Penal, Sala II", 4 de diciembre de 2019).

\section{La Suprema Corte bonaerense reafirmó la autonomía municipal}

La Suprema Corte de la Provincia de Buenos Aires se expidió en el marco de la acción originaria de inconstitucionalidad iniciada por el intendente de la Municipalidad de General San Martín, a la que adhirió el mandatario de la comuna de San Fernando, contra la Provincia de Buenos Aires.

El objeto de la causa consistió en la declaración de invalidez del decreto 1289/19 y del art. 104 de la ley 15.078 (presupuesto para el ejercicio 2019), incluyendo la solicitud del dictado de una medida cautelar que suspenda sus efectos durante el curso del proceso.

Vinculó el conflicto planteado con estas dos últimas manifestaciones de la autonomía municipal (económica y financiera), cuyo sostén normativo se halla en el art. 192 inc. 5 de la carta magna provincial, que establece como atribución inherente al 
régimen municipal la de votar anualmente su presupuesto y los recursos para costearlo, imponiendo en el mismo inciso el deber de establecer los recursos con los que afrontar las erogaciones no previstas en el presupuesto como recaudo para autorizar el dictado de una ordenanza especial.

Recordó en tal sentido que el art. 228 de la Ley Orgánica de Municipalidades (decreto ley 6769/58) establece que “...las facultades del gobierno municipal son irrenunciables e intransferibles y, en consecuencia, ninguna autoridad podrá imponer a las comunas gastos que ellas mismas no hayan autorizado, ni privarlas del derecho a invertir sus recursos en la forma en que dispongan sus poderes legalmente constituidos".

En esa misma dirección, con cita de jurisprudencia de la Corte Suprema de Justicia de la Nación, aludió a los debates de la Convención Constituyente en los que se destacó que el art. 123 de la Constitución Nacional "enlaza el principio de la autonomía municipal a la capacidad financiera de los municipios para ejercerla: los planos económico y financiero han sido especialmente considerados en el texto constitucional porque tienen una importancia superlativa. De esta manera estamos especificando y dejando en claro que los municipios argentinos van a poder (...) controlar sus propios recursos que, a su vez, podrán ser manejados independientemente de otro poder, complementando así facultades de administración que le son propias" (SCBA, "Intendente de la Municipalidad de General San Martín c/ Provincia de Bs.As. s/inconst. Decr. 1289/19 y Art. 104 Ley 15.078”, 27 de noviembre de 2019).

\section{Jurisprudencia Bonaerense}

\section{TRIBUNALES INFERIORES}

Tribunal: CÁMARA DE APELACIONES EN LO CIVIL Y COMERCIAL DE LA MATANZA, SALA I

Fallo: Salazar, Alexander Jonathan c. Reynoso, Alejandra Beatriz y Otros s/ nulidad de contrato - 19/03/2019 
Voces: Exceso en los honorarios, remuneración, contratos.

\section{Sumarios:}

- Varias personas celebraron un convenio de división de condominio. En el mismo negocio, si fijaron los porcentajes correspondientes a los honorarios de los letrados intervinientes. Solicitada judicialmente su reducción, la Cámara modificó lo dispuesto por el juez y acogió el pedido.

- El porcentaje de los honorarios del abogado dispuesto en un convenio de división de condominio - arribado con anterioridad a la mediación- debe reducirse, pues se observa una notable y extraordinaria desproporción entre las tareas profesionales realizadas y el monto que se obtendría de aplicar dicho porcentaje sobre el importe total obtenido en la venta de la cosa objeto del contrato, perjudicando claramente el patrimonio del deudor y violentando el derecho constitucional de propiedad.

\section{Extractos del decisorio:}

- “...la Sra.Juez de la instancia de grado, resolvió rechazar la demanda interpuesta por el Sr. Alexander Jonathan Salazar contra Verónica Andrea Cajal y Alejandra Beatriz Reynoso, (...)

- apeló la sentencia la parte actora..."

- "...la parte actora solicita y plantea la nulidad del convenio de honorarios a favor de la Dra. Reynoso Alejandra..."

- "...Las normas legales aplicables al presente "sub judice" que serán objeto de desarrollo en este primer voto, faculta a los magistrados a reducir equitativamente dichos estipendios honorificos, sin aniquilar los efectos de los contratos, reestableciendo las prestaciones en función del principio de proporcionalidad entre estas, es decir: "IIgual remuneración por igual tarea" (art. 14 bis, CN); todo ello, sin menoscabar las tareas profesionales..."

- “...Los jueces se hallan facultados para reajustar el importe de los honorarios convenidos en aquellos casos en que su monto resulte manifiestamente desproporcionado con relación a los intereses económicos que se encuentran en juego..." 
- “...cuando el convenio de honorarios exceda el porte máximo previsto en el asunto, deberá tenerse en cuenta que tal acuerdo no debe configurar un abuso de derecho, ni lesión ..."

- "...Los acuerdos celebrados en torno a los emolumentos, pueden ser - como se ha dicho-fijado por las partes, rigiendo asi la autonomía de la voluntad de los contratantes. No obstante, se indicó que la facultad volitiva no importa una regla absoluta puesto que estarían sujeto a los limites de normas superiores, independientemente de los propios que establece el referido ordenamiento arancelario..."

- El art. 55 de la ley 8904 establece que: "Para la determinación judicial de honorarios por trabajos extrajudiciales (...) cuando el beneficiario de los mismos lo solicitare se tendrán en cuenta las pautas minimas fijadas en el art. 9 y las normas generales establecidas en el art. 16 en lo que fueren aplicables".

- El art. 9 inc. 10 del arancel provincial bajo el subtítulo: "Arreglos extrajudiciales" determina como mínimo el $50 \%$ de las escalas fijadas para los mismos asuntos judiciales establecidas en la presente ley. Por su parte el art. 16 del mismo cuerpo legal, estatuye que para regular honorarios se tendrán en cuenta, el monto del asunto, su complejidad, el resultado obtenido, su trascendencia moral y económica, posición social y económica de las partes, tiempo empleado en la solución del litigio, entre otras pautas, etc.

- Asimismo, regula el art. 21 de la ley 8904 que en todos los procesos susceptibles de apreciación pecuniaria (...) el honorario del abogado será fijado entre el $8 \%$ y el $25 \%$ de su monto.

- Como se desprende de la norma, la ley establece un piso y un techo; es decir que, no se podrá percibir menos del piso ni más del techo. Estamos frente a un orden público a favor del profesional y otro orden público a favor del deudor, sobre la base del principio: favor debitoris, este último el cliente es la parte débil en la contratación, el inexperto, el profano frente al profesional universitario que cuenta con conocimiento jurídico y experiencia en el tema. 
- Desproporción entre el bonorario pactado:

- “...Nos encontramos ante la libertad de pactar los emolumentos profesionales y no obstante ello se reconoce algunos límites, como el abuso del derecho, la lesión subjetiva u objetiva o la teoría de la imprevisión, según su caso. Esos acuerdos de honorarios fijados por las partes se rigen por la autonomía de la voluntad. La doctrina ha indicado que la facultad volitiva no importa una regla absoluta, porque están sujetas a la límites de normas superiores..."

- “...En cuanto al control judicial de los convenios de bonorarios y las facultades del juez, el magistrado está autorizado a controlar la legalidad del contrato de honorarios. De este modo, se advierte que si existe algún vicio, desequilibrio en las prestaciones, atentado contra la moral y las buenas costumbre, etc., podrá moderar el convenio..."

- una notable y extraordinaria desproporción entre las tareas profesionales realizadas por el letrado y el monto que se obtendría de aplicar el porcentaje del $20 \%$ (convenido de honorarios), sobre el monto total obtenido en la venta de la cosa objeto de división de condominio, siendo esta el monto de la base jurídica a los efectos de cuantificar económicamente el monto de los estipendios honoríficos.

- “...En efecto, esa desproporción que existe entre las tareasrealizadas y el monto que se obtendría de los honorarios, viola fundamentalmente preceptos jurídicos de orden constitucional, en perjuicio patrimonial del deudor ..."

- el honorario debe guardar proporcionalidad con las tareas realizadas por los letrados en la etapa de mediación obligatoria.

- “...En suma, corresponde que esta Alzada morigere equitativamente las bases contractuales suscriptas por las partes, sentenciando a modo de propuesta en este voto, lo siguiente: $\left.1^{\circ}\right)$ Establecer que la base tenida en cuenta a los efectos de aplicar el porcentaje legal honorifico, será el $50 \%$ del valor de venta fijado en el acuerdo celebrado ante la mediadora 
de división de condominio, porque precisamente la asistencia letrada acreedora de la suma de dinero está asesorando y defendiendo ese porcentaje del condominio; $2^{\circ}$ ) Fijar en concepto de remuneración por los servicios profesionales prestados por la demandada, logrando de ese modo y forma un equilibrio en el sinalagma contractual, esto es un equilibrio entre las prestaciones asumidas por las partes, el porcentaje del $10 \%$ sobre la base regulatoria fijada precedentemente en el punto primero..."

- "...la labor desarrollada por la mediadora ha sido exitosa, por cuanto se obtuvo como resultado un convenio suscripto por las partes estableciendo el modo y forma de división del condominio, evitándose de ese modo una contienda judicial..."

- "...Modificar la sentencia apelada de la siguiente manera: a) Hacer lugar parcialmente a la demanda entablada y en su consecuencia: b) Establecer que la base tenida en cuenta a los efectos de aplicar el porcentaje legal bonorífico, será el $50 \%$ del valor de venta fijado en el acuerdo celebrado ante la mediadora de división de condominio. c) Fijar en concepto de remuneración por los servicios profesionales prestados por la demandada, en el porcentaje del $10 \%$ más sus accesorios previsionales e IVA si correspondiere, sobre la base regulatoria fijada precedentemente en el punto b). $2^{\circ}$ ) Confirmar el resto de la sentencia apelada en cuanto ha sido materia de agravios..."

Tribunal: CÁMARA DE APELACIONES EN LO CIVIL Y COMERCIAL DE AZUL, SALA II

Fallo: Ferreira, Alba Eliana Soledad c. Meaca Ascazuri, Pedro Hernán y otros s/ Daños y perj. Autom. c/les. o muerte (Exc. Estado) 27/08/2019

Voces: Daños. Responsabilidad Civil, Código Civil y Comercial, Accidentes, daño extra patrimonial.

\section{Sumarios:}

- El propietario de un camión que colisionó con una motocicleta en ocasión de ingresar aquel vehículo en un garaje virando a la derecha debe responder por las consecuencias 
dañosas derivadas del hecho, en tanto se acreditó la intervención causal activa del vehículo del demandado y que el proceso material y todas las secuencias del embestimiento culminaron con la motocicleta bajo las ruedas traseras del camión, lo que constituye el presupuesto de hecho de la aplicación de la teoría del riesgo creado (art. 1113, Cód. Civil derogado).

- El planteo de la aseguradora citada, en garantía relativo a que la víctima del accidente de tránsito debe acreditar todos los presupuestos de la responsabilidad civil, debe rechazarse, pues, tratándose de responsabilidad objetiva por riesgo creado, el responsable presunto debe alegar y acreditar las eximentes que invoca (arts. 1721, 1722, 1723, 1757, 1758, 1769 y concs., Cód. Civ. y Com. de la Nación).

- El art. 1746 del Cód. Civ. y Com. de la Nación, para el daño por incapacidad, pero también aplicable al art. $1745 \mathrm{del}$ Cód. Civ. y Com. de la Nación por muerte, ha traído una innovación sustancial pues prescribe el deber de aplicar fórmulas matemáticas tendientes a calcular el valor presente de una renta futura no perpetua.

- La indemnización por daño moral, otorgada a un motociclista que colisionó con un camión, debe elevarse -en el caso, a \$500.000—, pues, más allá de la capacidad resiliente de la víctima, las secuelas y secuencias posteriores al hecho requeridas durante su recuperación afectaron su vida familiar (el padre tenía cáncer avanzado y la noticia lo angustió) y requirió la asistencia de la madre, además de influir negativamente en su expectativa de cambio de trabajo y de ingreso a la policía, lo que se vio frustrado a raíz del hecho.

\section{Extractos del decisorio:}

- "I. La sentencia de Primera Instancia hizo lugar a la demanda resarcitoria de daños y perjuicios, morales y patrimoniales, promovida por Eliana Soledad Ferreira Alba contra Macro Visión SA, haciendo extensiva la condena a la citada en garantía "Compañía de Seguros La Mercantil Andina SA", en la medida de la cobertura contratada, condenándolos en forma 
solidaria a pagar la suma de $\$ 575.800$, con más intereses desde la fecha del hecho, 07 de Marzo de 2016, a la tasa pasiva más alta, aclarándose que a partir de su implementación resulta ser la tasa pasiva digital. Impuso las costas a los demandados vencidos y difirió la regulación de honorarios para su oportunidad.

- El becho se produjo cuando ambos vebículos circulaban por la Avenida Del Valle de aquella ciudad, en sentido Oeste a Este, y en ocasión de llegar el camión a la altura del número 5098 (a mitad de cuadra) giró hacia su derecha para entrar al estacionamiento del negocio denominado "La Casa de los Hierros", embistiendo el vebículo de mayor porte el lateral izquierdo de la motocicleta de la actora provocándole su caída y posteriores lesiones [+] En lo atinente a los daños resarcibles otorgó la suma de $\$ 340.000$ en concepto de daño físico y psíquico de Eliana S. Ferreira Alba, tal como se desprende de la pericia médica obrante a fs. 167/179 que informa que presenta secuelas que determinan una incapacidad permanente, parcial y definitiva del 31,15\% o 38,82\% según el tipo de baremo que se utilice para su cálculo. Para cuantificar el referido daño sobre incapacidad sobreviniente acudió a la aplicación de una fórmula polinómica computando como variables la edad de la actora -20 años - al momento del hecho, que trabajaba en la Heladería "Grido" y que a esa fecha el Salario Mínimo, Vital y Móvil era de \$4.716. Consideró también una tasa de descuento del 4 \% y computó la edad de 65 años. Sobre dicha base, y luego de efectuar otras consideraciones, cuantificó en la suma referida (\$340.000) el daño material por incapacidad. Por otro lado otorgó \$200.000 en concepto de daño moral atendiendo a las angustias y padecimientos a los que se vio sometida Eliana S. Ferreira Alba y que conforme el art. 1741 del Cód. Civ. y Com. de la Nación dicho daño es presumido. Desestimó el daño psicológico porque la pericia de fs. 304/313 y aclaraciones de fs. 316/317 indican que la actora no sufrió trauma psíquico ni requiere de tratamiento psicoterapéutico. Más adelante cuantificó en \$15.000 los gastos médicos y asistenciales ya que la actora recibió tratamientos y atenciones médica y kinesiológica 
que están mencionadas en la pericia de médica de fs. 260 y 266. Finalmente fijó en $\$ 20.800$ el reclamo por daños materiales al ciclomotor, conforme el presupuesto reconocido de fs. 219/220 y que el referido vebículo sufrió destrucción total (arts. 43 incs. a, b, d de la Ley 24.449 y Ley 26.363).

- II. 1.- Anticipo mi opinión en el sentido de que la responsabilidad civil en el hecho en discusión recayó exclusivamente en el conductor del camión por lo que la demandada Macro Visión SA debe responder por la totalidad del daño causado (arts. 901, 906, 1113 Cód. Civil; arts. 1769, 1757, 1758 y concs. Cód. Civ. y Com. de la Nación).

- - - receptada en el actual art. 1769 del Cód. Civ. y Com. de la Nación-, los siniestros viales se rigen por las reglas de la responsabilidad objetiva contemplada en el art. 1113 del Cód. Civil (aplicable al caso en razón de la fecha del siniestro; art. 7 Cód. Civ. y Com. de la Nación), tal como lo ha decidido la sentencia de grado.

- La demandada no probó de modo claro y asertivo que se hubiere configurado dicha eximente, esto es -conforme lo expresan ambas coaccionadas en la expresión de agraviosque el camión embistiera a la moto sobre la vereda.

- El punto de partida es que no está en discusión que la motocicleta estaba caída, y resultó aprisionada, por las ruedas traseras derechas del camión; y en éstas circunstancias se produjeron los daños patrimoniales y morales de la actora. En otras palabras: la motocicleta como consecuencia final del siniestro vial quedó caída, y gravemente dañada, al igual que su conductora, sobre la vereda o sector de ingreso a un playón de la empresa existente en Avenida del Valle a la altura del número 5000, estando el camión en sentido perpendicular, esto es ingresando al referido playón desde la avenida, tal como resulta con claridad de las abundantes fotografías agregadas a la causa penal, del croquis ilustrativo, del acta de reconocimiento y de la pericia accidentológica de la Subcomisario Martina García, y la pericia planimétrica del comisario Ricardo Kriger (...) Con 
ello quiero significar que está acreditada la intervención causal activa del vehículo del demandado y que el proceso material y todas las secuencias del embestimiento culminaron con la motocicleta bajo las ruedas traseras del camión, lo que constituye el presupuesto de hecho de la aplicación de la teoría del riesgo creado (art. 1113 Cód. Civil).

- En conclusión: el embestimiento de la moto se produjo sobre la avenida y el camión en su giro hacia la derecha para ingresar a una empresa a mitad de cuadra de la Avenida del Valle roza a la motocicleta, y la "arrastra hacia la vereda, lugar en el que se detiene" (arts. 1113 y concs. Cód. Civil; y 1769, 1757, 1758 y concs. Cód. Civ. y Com. de la Nación; arts. 36, 39 inc. b, 43 incs. $a, b, c, d, 50,64$ y concs. Ley 13.927).

- Anticipo que su cuantía debe ser aumentada (arts. 1737, 1738, 1740, 1746 y concs. Cód. Civ. y Com. de la Nación).

- la demandante presenta "secuela funcional y estética producto de fractura de escápula, extremidad distal de búmero y cabeza de radio izquierdas, asociados a scalp

- El art. 1746 Cód. Civ. y Com. de la Nación, para el daño por incapacidad, pero también aplicable al art. 1745 Cód. Civ. y Com. de la Nación por muerte, ha traído una innovación sustancial pues prescribe el ,deber" de aplicar fórmulas matemáticas tendientes a calcular el valor presente de una renta futura no perpetua.

- En suma; la cuantía indemnizatoria por la incapacidad de la actora que corresponde asciende a $\$ 1.100 .000$ a la fecha (arts. 1746 y concs. Cód. Civ. y Com. de la Nación).

- El agravio de las demandadas solicitando se reduzca el daño moral no es procedente y corresponde su aumento, conforme lo solicita la actora.

- “...Soy de la opinión que la suma por éste concepto debe fijarse en \$500.000 (...) Más allá de la capacidad resiliente de Eliana Soledad Ferreira Alba las secuelas y secuencias posteriores al becho requeridas durante su recuperación afectaron su vida familiar (su padre tenía un cáncer avanzado y la noticia 
del accidente lo angustió) y requirió de la asistencia de su madre, además de influir negativamente en su expectativa de cambio de trabajo y de ingreso a la policía lo que se vio frustrado a raíz del becho..."

- Por todo lo expuesto la suma de \$500.000 en concepto de daño extrapatrimonial le permitirá a la actora adquirir bienes de consumo (televisor, equipos de música, etc.) o efectuar un viaje incluso fuera del país que le permita acceder a placeres compensatorios y sustitutivos de la lesión emocional y espiritual sufrida.

\section{SUPREMA CORTE DE LA PROVINCIA DE BUENOS AIRES}

Fallo: Agosto, Guillermo Elvio Fabián c. Gobierno de la Provincia de Buenos Aires s/ Accidente de trabajo - acción especial - 19/02/2020

Voces: Incapacidad de carácter físico, error de cálculo.

\section{Sumarios}

- La definición del fallo con arreglo a la cual se fijó un 65,7 \% de incapacidad de carácter físico al actor resulta absurda, pues proviene de un error grosero y manifiesto, resultante -en el caso- de la circunstancia de que esa conclusión se asienta en una pericia carente de rigor científico.

\section{Extracto del decisorio:}

- El Tribunal de Trabajo $N^{o} 1$ con asiento en la ciudad de Avellaneda hizo lugar parcialmente a la acción deducida,

- Se interpuso, por el Fisco provincial, recurso extraordinario de inaplicabilidad de ley

- En lo que interesa, el tribunal de grado admitió la demanda promovida por el señor Guillermo Elvio Fabián Agosto - quien se desempeñaba como oficial de policía con funciones en la Comisaría Seccional 7ma. de Avellaneda-y, en consecuencia, condenó a la Provincia de Buenos Aires (en su condición de empleadora autoasegurada) al pago de las prestaciones 
dinerarias por incapacidad laboral permanente total previstas en el régimen especial de reparación de infortunios laborales que juzgó aplicable al caso —leyes 24.557 y 26.773-, como derivación del accidente de trabajo que protagonizó.

- Para así decidir, tuvo por acreditada la existencia del infortunio, ocurrido —señaló- el día 17 de junio de 2013 cuando, encontrándose el actor realizando un operativo de rastrillaje en la localidad de Villa Corina, al intentar saltar una terraza, tropezó, cayó y sufrió lesiones en su mano y muñeca derecha, que le provocan una minusvalía —con la incidencia de los distintos factores de ponderación-del 65, 7\% del indice de la total obrera, y una reacción vivencial anormal de grado III, que lo incapacita en un $15 \%$ adicional. En ese orden, concluyó que el señor Agosto presenta una incapacidad del 80,7\% (v. vered., segunda cuestión, fs. 273 vta. y 274).

- Establecido lo anterior, en la sentencia concluyó que al accionante le correspondía percibir las prestaciones dinerarias contempladas en los arts. 11 apartado 4 inc. " $b$ " (conf. art. 2, resol. de la Secretaría de Seguridad Social del Ministerio de Trabajo, Empleo y Seguridad Social de la Nación 34/13) y 15 de la ley 24.557; así como la indemnización adicional prevista en el art. 3 de la ley 26.773 (conf. art. 6 inc. "b", resol. cit.; v. sent., fs. 276 vta./277vta.).

- Contra dicho pronunciamiento la Fiscalía de Estado de la Provincia de Buenos Aires interpone recurso extraordinario de inaplicabilidad de ley (...) el juzgador de grado incurrió en absurdo al determinar el grado de incapacidad que afecta al actor.

- En efecto, pese a que los integrantes del tribunal fundaron su conclusión sobre el tópico en cuestión en el contenido de la indicada experticia, reconociéndole eficacia a este medio probatorio ( $v$. vered., segunda cuestión, fs. 274), entiendo -contrariamente a lo concluido por el juzgador de origenque ni bien se repara en las breves consideraciones que contiene la pericia realizada, su carencia de fundamento científico se observa manifiesta. 
- Ello, a mi juicio, se patentiza -aun cuando no se me escapa que el profesional interviniente solicitó estudios complementarios que bubo de contemplar (v. fs. 209, 211, 249 y 255 vta.) - en el hecho de que por la sola fractura del escafoides sufrida por el actor, incluso considerando las limitaciones en el miembro superior, artrosis y osteoporosis producidas por la alteración en la actividad del brazo, el profesional otorgó un grado de incapacidad extremadamente elevado (50\%) que, incluyendo los factores de ponderación alcanzó el $67,5 \%$, sin que de la lectura del dictamen se adviertan argumentos que permitan justificar razonablemente dicha estimación.

- "...la definición del fallo con arreglo a la cual se fijó un $65,7 \%$ de incapacidad de carácter físico al actor resulta absurda, pues proviene de un error grosero y manifiesto, resultante - en el caso- de la circunstancia de que esa conclusión se asienta en una pericia carente de rigor científico..."

- “...corresponde hacer lugar parcialmente al recurso extraordinario de inaplicabilidad de ley deducido y, en consecuencia, revocar la sentencia en cuanto incurrió en absurdo al fijar el porcentaje de incapacidad física del actor con arreglo a la eficacia probatoria que le atribuyó al dictamen pericial producido...";

- "...se hace lugar parcialmente al recurso extraordinario de inaplicabilidad de ley traído y se revoca la sentencia impugnada en cuanto incurrió en absurdo, con el alcance establecido en el punto IV del voto emitido en primer término. En consecuencia, se remiten los autos al tribunal de origen para que, debidamente integrado, dicte nuevo pronunciamiento..."

Fallo: Zárate Maldonado, Alexis Joel s/ Recurso extraordinario de inaplicabilidad de ley en causa $n^{\circ} 87.295$ del Trib. Cas. Pen., Sala II - 04/12/2019

Voces: Recurso de inaplicabilidad de ley, Abuso sexual, arbitrariedad. 


\section{Sumario:}

- El recurso de inaplicabilidad de ley interpuesto para impugnar la condena al imputado por el delito de abuso sexual con acceso carnal debe ser rechazado, pues si bien los recurrentes formulan otras interpretaciones posibles respecto del valor de convicción de los indicios aislados, omiten hacer un análisis conjunto de todos ellos, tal como fueron considerados por el tribunal del juicio - y convalidado por el revisor- para fundar los extremos de la imputación y la autoría responsable, y no se observa arbitrariedad en las formulaciones del tribunal casatorio con las que dio respuesta a cada uno de los reclamos de la defensa y expuso los argumentos y razones que confirman la falta de consentimiento de la víctima al momento del hecho, no desde la apreciación parcelada de los diversos elementos de prueba, sino con una visión de conjunto.

- Si bien es posible que numerosos indicios considerados cada uno individualmente no alcancen para probar la autoría, en su conjunto le pueden proporcionar la convicción de la intervención y culpabilidad del acusado en el hecho, siendo de este tenor en definitiva lo acaecido en el caso.

\section{Extractos del decisorio:}

- La Sala II del Tribunal de Casación Penal, mediante el pronunciamiento dictado el 3 de mayo de 2018, rechazó, en lo que aquí interesa, el recurso de la especialidad interpuesto por el defensor de confianza de Alexis Joel Zárate Maldonado contra la sentencia del Tribunal en lo Criminal $N^{o} 1$ del Departamento Judicial de Lomas de Zamora, que condenó al nombrado a la pena de seis años y seis meses de prisión, accesorias legales $y$ costas, por resultar autor responsable de abuso sexual con acceso carnal

- Frente a lo así decidid o, los defensores (...) interpusieron recurso extraordinario de inaplicabilidad de ley

- Los letrados de confianza del imputado Alexis Joel Zárate Maldonado denuncian la errónea aplicación de los arts. 18 y 19 de la Constitución nacional; 15, 16 y 168 de su 
par provincial; 45 y 119 tercer párrafo del CP y de las normas rituales que cita (v. fs. 313).

- Cuestionan el reproche penal efectuado contra su asistido por el delito de abuso sexual con acceso carnal, cuando, insistiendo con los agravios formulados en las instancias previas, a su criterio, el hecho tal como ba sido intimado no ba podido acreditarse.

- “...La materialidad ilícita que el tribunal de primera instancia tuvo por legalmente comprobada da cuenta que „...el día 16 de marzo del año 2014 y siendo alrededor de las 07:30 horas, en el departamento planta baja, sito en la calle ... $N^{o} \ldots$, de la localidad de Wilde, partido de Avellaneda, un sujeto del sexo masculino mayor de edad, identificado como Alexis Joel Zarate, irrumpió en la habitación en la que se encontraba durmiendo P. U. G. B. y la accedió carnalmente..."

- “...el a quo descartó cualquier posible violación al principio de congruencia, ligeramente anunciada a remolque de lo anterior, en tanto, sostuvo, que del repaso de las constancias del legajo se advierte inalterable la materialidad fáctica achacada, cuando, de su parte, el recurrente no se ha ocupado de apuntar alguna variación relevante susceptible de justificar la infracción alegada ( $v$. fs. 274). Tal afirmación también llega sin réplica idónea susceptible de revertir tal aserto..."

- "Si bien los recurrentes formulan otras interpretaciones posibles respecto del valor de convicción de los indicios aislados, omiten hacer un análisis conjunto de todos ellos, tal como fueron considerados por el tribunal del juicio $-y$ convalidado por el revisor-para fundar los extremos de la imputación y la autoría responsable"

- “...no encuentro arbitrarias las formulaciones del tribunal casatorio con las que dio respuesta a cada uno de los reclamos de la defensa y expuso los argumentos y razones que confirman la falta de consentimiento de la víctima al momento del becho, no desde la apreciación parcelada de los diversos elementos de prueba, sino con una visión de conjunto..." 
- “...si bien es posible que numerosos indicios considerados cada uno individualmente no alcancen para probar la autoría, en su conjunto le pueden proporcionar al tribunal la convicción de la intervención y culpabilidad del acusado en el hecho..."

- “...En lo tocante a la regulación de bonorarios y conforme los lineamientos sentados por esta Corte en el Acuerdo 3871 de 25/10/2017, resulta aplicable el régimen arancelario del decreto ley 8904/1977 en razón de que se ha efectuado una valoración del trabajo en cuestión a partir de una presentación anterior a la vigencia del nuevo régimen de la ley 14.967, a la luz de la observación efectuada por el Poder Ejecutivo al contenido del art. 61 de dicha ley que establecía la aplicación del nuevo régimen a todos los procesos en los que, al tiempo de su promulgación, no exista resolución firme sobre regulación de honorarios al considerar que la aplicación retroactiva de la misma podría vulnerar derechos adquirido (...) se rechaza el recurso extraordinario de inaplicabilidad de ley interpuesto". 